\title{
Enhanced Oil Recovery - An Overview
}

\author{
S. Thomas \\ PERL Canada Ltd., Canada \\ e-mail: sarathomas@shaw.ca
}

\begin{abstract}
Résumé - Récupération assistée du pétrole : panorama - Près de 2,0 $\times 10^{12}$ barils $\left(0,3 \times 10^{12} \mathrm{~m}^{3}\right)$ de pétrole conventionnel et $5,0 \times 10^{12}$ barils $\left(0,8 \times 10^{12} \mathrm{~m}^{3}\right)$ de pétrole lourd resteront dans les réservoirs du monde entier lorsque les méthodes de récupération traditionnelles auront été épuisées. Une grande partie de ce pétrole serait récupéré grâce à des méthodes de Récupération Assistée du Pétrole (EOR), qui fait partie du projet général de Récupération Améliorée du Pétrole (IOR). Le choix de la méthode et la récupération escomptée dépendent de nombreuses considérations économiques et technologiques. Cet article étudie les méthodes EOR qui ont été testées sur le terrain. Certaines ont été une réussite commerciale, tandis que d'autres sont d'un intérêt essentiellement académique. Les raisons en sont discutées. L'article examine les méthodes de récupération du pétrole thermique et non thermique. Elles sont présentées de façon équilibrée, en prenant en compte le succès commercial sur le terrain. Seules quelques méthodes de récupération ont connu une réussite commerciale, tels que les processus d'injection de vapeur dans les pétroles lourds et les sables bitumineux (si le réservoir offre des conditions favorables pour de telles applications) et de dioxyde de carbone miscible pour les réservoirs de pétrole léger. D'autres méthodes de récupération ont été testées, et ont même permis d'augmenter la récupération d'huile mais comportent des limites inhérentes. Les technologies EOR actuelles sont présentées dans une perspective appropriée, soulignant les raisons techniques au manque de réussite. Les méthodes d'amélioration de la récupération de pétrole, en particulier celles visant à diminuer la saturation interstitielle du pétrole, ont fait l'objet d'une attention particulière dans les laboratoires et sur le terrain. Les nombreux documents qui traitent du sujet donnent l'impression qu'il est relativement simple d'augmenter la récupération de pétrole au-delà de la récupération secondaire (en assumant que le réservoir se prête à une récupération primaire et secondaire). Il s'avère que ce n'est pas le cas. De nombreux réservoirs adaptés à l'injection de vapeur et au dioxyde de carbone ont déjà été exploités et arrivent à maturité. D'autres méthodes EOR rencontrent des limites qui ne sont pas liées à des facteurs économiques. La récupération du pétrole supplémentaire est complexe et coûteuse, et s'est révélé probante seulement pour quelques processus et ce, dans des conditions astreignantes. Néanmoins, l'EOR continuera d'avoir une place importante dans la production pétrolière, en raison de l'intensification de la demande en énergie et de l'offre limitée. Un important travail de recherche doit être mené à bien pour développer des technologies de récupération sur les deux tiers du pétrole qui ne sera pas récupéré dans les réservoirs. Des références clés sont indiquées.
\end{abstract}

\footnotetext{
Abstract - Enhanced Oil Recovery: An Overview - Nearly $2.0 \times 10^{12}$ barrels $\left(0.3 \times 10^{12} \mathrm{~m}^{3}\right)$ of conventional oil and $5.0 \times 10^{12}$ barrels $\left(0.8 \times 10^{12} \mathrm{~m}^{3}\right)$ of heavy oil will remain in reservoirs worldwide after conventional recovery methods have been exhausted. Much of this oil would be recovered by Enhanced Oil Recovery (EOR) methods, which are part of the general scheme of Improved Oil Recovery $(I O R)$. The choice of the method and the expected recovery depends on many considerations, economic as well as technological. This paper examines the EOR methods that have been tested in the field. Some
} 
of these have been commercially successful, while others are largely of academic interest. The reasons for the same are discussed. The paper examines thermal and non-thermal oil recovery methods. These are presented in a balanced fashion, with regard to commercial success in the field. Only a few recovery methods have been commercially successful, such as steam injection based processes in heavy oils and tar sands (if the reservoir offers favourable conditions for such applications) and miscible carbon dioxide for light oil reservoirs. Other recovery methods have been tested, and even produced incremental oil, but they have inherent limitations. The current EOR technologies are presented in a proper perspective, pointing out the technical reasons for the lack of success. Methods for improving oil recovery, in particular those concerned with lowering the interstitial oil saturation, have received a great deal of attention both in the laboratory and in the field. From the vast amount of literature on the subject, one gets the impression that it is relatively simple to increase oil recovery beyond secondary (assuming that the reservoir lends itself to primary and secondary recovery). It is shown that this is not the case. Many reservoirs suitable for steam injection and carbon dioxide have already been exploited and are approaching maturity. Other EOR methods suffer from limitations that have little to do with economics. Recovering incremental oil is complex and costly, and has been successful only for a few processes under exacting conditions. Nevertheless, EOR will continue to have an important place in oil production, in view of the escalating energy demand and the tight supply. It is suggested that much research is needed to develop technologies for recovering over two-thirds of the oil that will remain unrecovered in reservoirs. Key references are indicated.

\section{IOR vs. EOR}

The terms EOR and IOR have been used loosely and interchangeably at times. IOR, or improved oil recovery, is a general term which implies improving oil recovery by any means. For example, operational strategies, such as infill drilling and horizontal wells, improve vertical and areal sweep, leading to an increase in oil recovery. Enhanced oil recovery, or EOR, is more specific in concept, and it can be considered as a subset of IOR. EOR implies a reduction in oil saturation below the residual oil saturation $\left(\mathrm{S}_{\mathrm{or}}\right)$. Recovery of oils retained due to capillary forces (after a waterflood in light oil reservoirs), and oils that are immobile or nearly immobile due to high viscosity (heavy oils and tar sands) can be achieved only by lowering the oil saturation below $\mathrm{S}_{\text {or }}$. Miscible processes, chemical floods and steambased methods are effective in reducing residual oil saturation, and are hence EOR methods. The main focus of this paper is on EOR methods.
The target of EOR varies considerably for the different types of hydrocarbons. Figure 1 shows the fluid saturations and the target of EOR for typical light and heavy oil reservoirs and tar sands. For light oil reservoirs, EOR is usually applicable after secondary recovery operations, and the EOR target is $\sim 45 \%$ OOIP. Heavy oils and tar sands respond poorly to primary and secondary recovery methods, and the bulk of the production from such reservoirs come from EOR methods.

\section{RECOVERY OF RESIDUAL OIL}

Mobilization of residual oil is influenced by two major factors: Capillary Number $\left(N_{c}\right)$ and Mobility Ratio $(M)$. Capillary Number is defined as $N_{c}=v \mu / \sigma$, where $v$ is the Darcy velocity $(\mathrm{m} / \mathrm{s}), \mu$ is the displacing fluid viscosity (Pa.s) and $\sigma$ is the interfacial tension $(\mathrm{N} / \mathrm{m})$. The most effective and practical way of increasing the Capillary Number is by

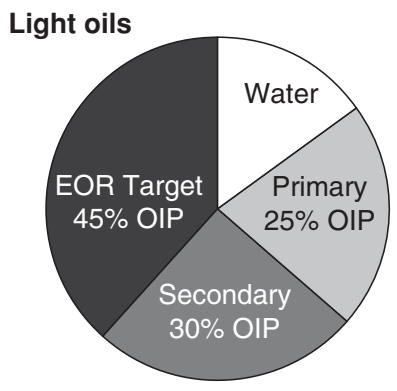

Figure 1

EOR targt for different hydrocarbons.
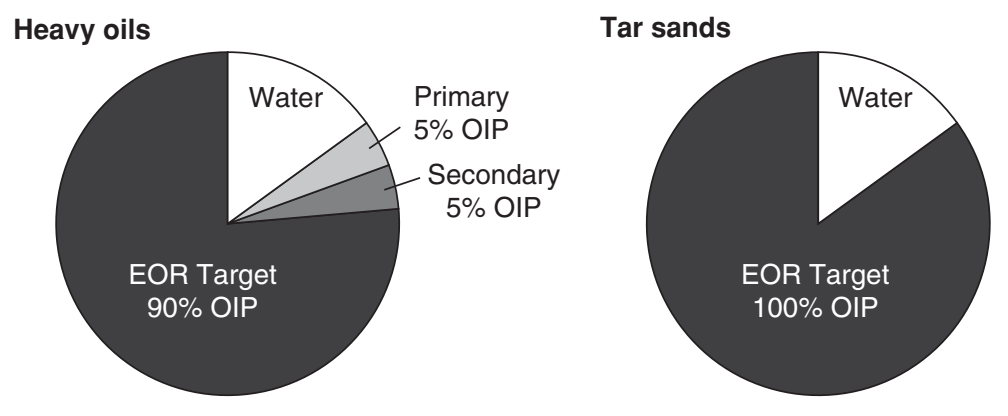

(Assuming Soi $=85 \% \mathrm{PV}$ and $\mathrm{Sw}=15 \% \mathrm{PV}$ )

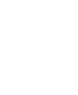

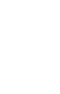


reducing $\sigma$, which can be done by using a suitable surfactant or by the application of heat. An approximation of the effect of Capillary Number on residual oil saturation is shown in Figure 2. Capillary number at the end of a waterflood is $\sim 10^{-7}$. A $50 \%$ reduction in residual oil saturation requires that the Capillary Number be increased by 3 orders of magnitude. Capillary number in a miscible displacement becomes infinite, and under such conditions, residual oil saturation in the swept zone can be reduced to zero if the mobility ratio is "favourable".

Mobility ratio is defined as $M=\lambda_{\text {ing }} / \lambda_{\text {ed }}$, where $\lambda_{\text {ing }}$ is the mobility of the displacing fluid (e.g. water), and $\lambda_{e d}$ is the mobility of the displaced fluid (oil). ( $\lambda=k / \mu$, where $k$ is the effective permeability, $\left(\mathrm{m}^{2}\right)$ and $\mu$ is the viscosity (Pa.s) of the fluid concerned). Mobility ratio influences the microscopic (pore level) and macroscopic (areal and vertical sweep) displacement efficiencies. A value of $M>1$ is considered unfavourable, because it indicates that the displacing fluid flows more readily than the displaced fluid (oil), and it can cause channelling of the displacing fluid, and as a result, bypassing of some of the residual oil. Under such conditions, and in the absence of viscous instabilities, more displacing fluid is needed to obtain a given residual oil saturation. The effect of mobility ratio on displaceable oil is shown in Figure 3, the data for which was obtained from calculations using Buckley-Leverett theory for waterflooding. The three curves represent 1,2 and 3 pore volumes of total fluid injected, respectively. Displacement efficiency is increased when $M=1$, and is denoted a "favourable" mobility ratio.

\section{EOR METHODS}

Many EOR methods have been used in the past, with varying degrees of success, for the recovery of light and heavy oils, as well as tar sands. A general classification of these methods is shown in Figure 4. Thermal methods are primarily intended for heavy oils and tar sands, although they are applicable to light oils in special cases. Non-thermal methods are normally used for light oils. Some of these methods have been tested for heavy oils, however, have had limited success in the field. Above all, reservoir geology and fluid properties determine the suitability of a process for a given reservoir. Among thermal methods, steam-based methods have been more successful commercially than others. Among non-thermal methods, miscible flooding has been remarkably successful, however applicability is limited by the availability and cost of solvents on a commercial scale. Chemical methods have generally been uneconomic in the past, but they hold promise for the future. Among immiscible gas injection methods, $\mathrm{CO}_{2}$ floods have been relatively more successful than others for heavy oils.

\subsection{Thermal Methods}

Thermal methods have been tested since 1950's, and they are the most advanced among EOR methods, as far as field experience and technology are concerned. They are best suited for heavy oils $\left(10-20^{\circ}\right.$ API) and tar sands $\left(\leq 10^{\circ}\right.$ API). Thermal methods supply heat to the reservoir, and vaporize some of the oil. The major mechanisms include a large reduction in viscosity, and hence mobility ratio. Other mechanisms, such as rock and fluid expansion, compaction, steam distillation and visbreaking may also be present. Thermal methods have been highly successful in Canada, USA, Venezuela, Indonesia and other countries.

\subsubsection{Cyclic Steam Stimulation (CSS)}

Cyclic steam stimulation [1] is a "single well" process, and consists of three stages, as shown in Figure 5. In the initial

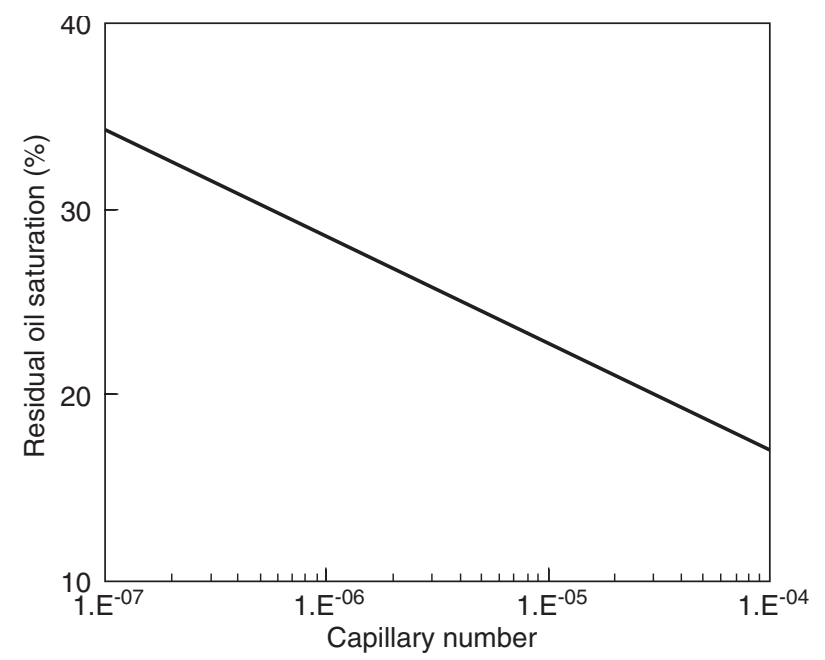

Figure 2

Effect of capillary number on residual oil saturation.

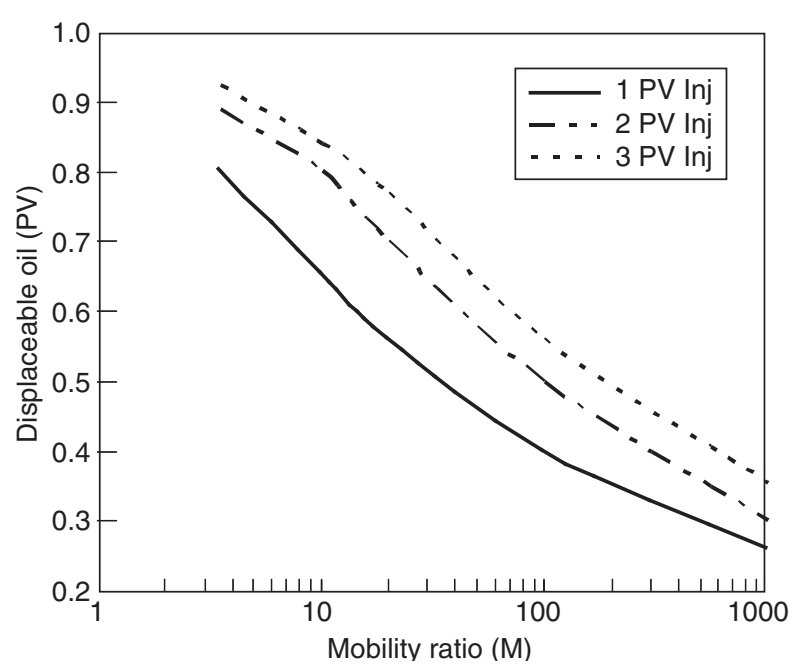

Figure 3

Effect of mobility ratio on displaceable oil. 


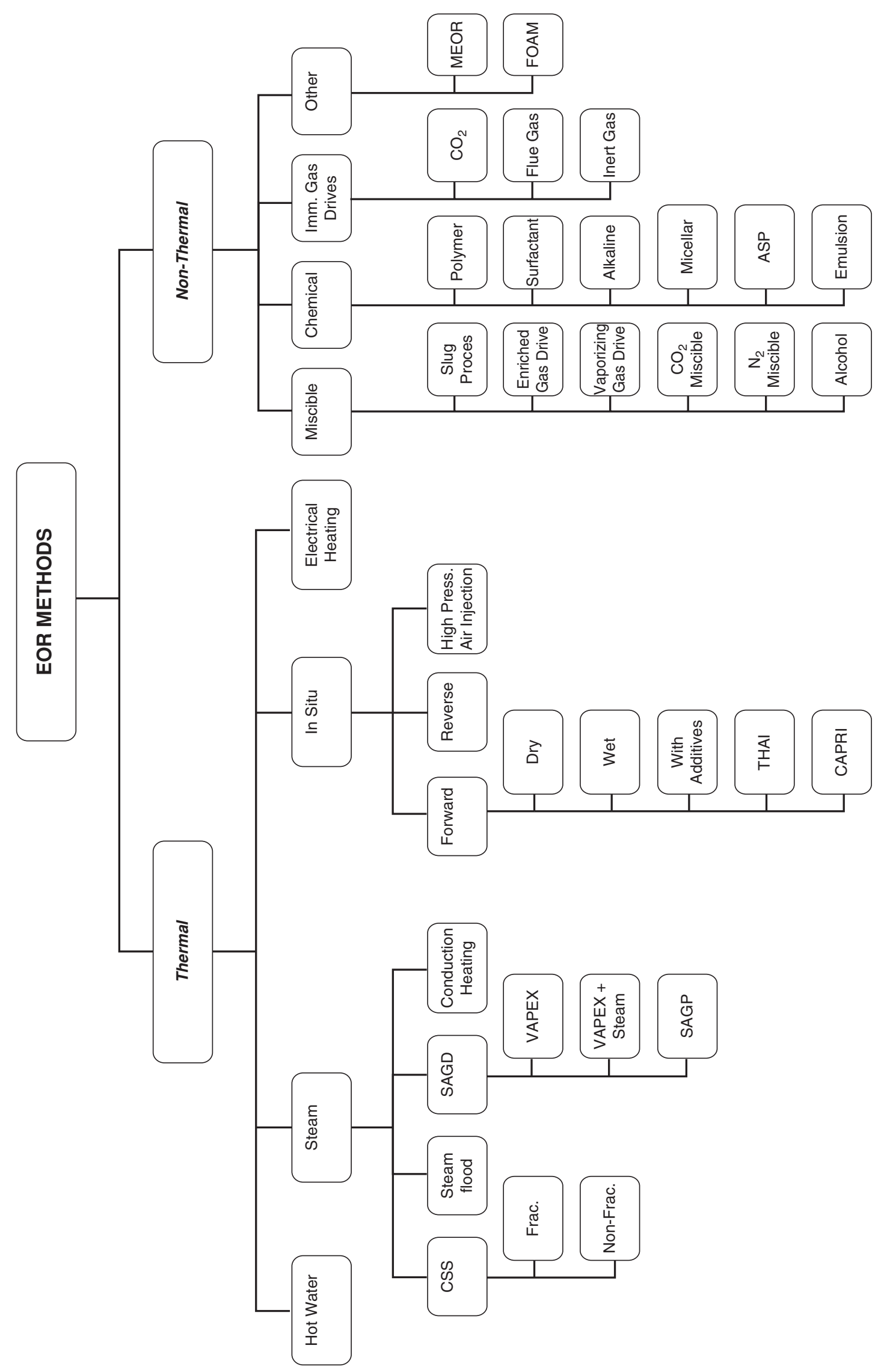



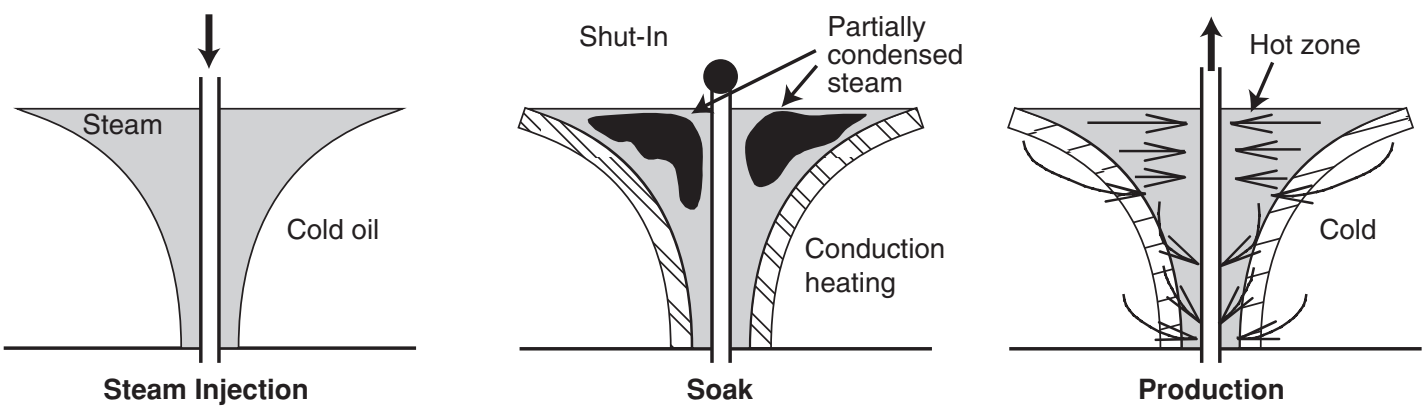

Figure 5

Cyclic Steam Stimulation (CSS).

stage, steam injection is continued for about a month. The well is then shut in for a few days for heat distribution, denoted by soak. Following that, the well is put on production. Oil rate increases quickly to a high rate, and stays at that level for a short time, and declines over several months. Cycles are repeated when the oil rate becomes uneconomic. Steam-oil ratio is initially 1-2 or lower, and it increases as the number of cycles increase. Near-wellbore geology is important in CSS for heat distribution as well as capture of the mobilized oil. CSS is particularly attractive because it has quick payout, however, recovery factors are low (10-40\% OIP). In a variation, CSS is applied under fracture pressure [2]. The process becomes more complex as communication develops among wells.

\subsubsection{Steamflooding}

Steamflooding [3-5] is a pattern drive, similar to waterflooding, and performance depends highly on pattern size and geology. Steam is injected continuously, and it forms a steam zone which advances slowly. Oil is mobilized due to viscosity reduction. Oil saturation in the swept zone can be as low as $10 \%$. Typical recovery factors are in the range $50-60 \%$ OIP. Steam override and excessive heat loss can be problematic.

\subsubsection{Steam Assisted Gravity Drainage (SAGD)}

SAGD was developed by Butler [6] for the in situ recovery of the Alberta bitumen. The process relies on the gravity segregation of steam, utilizing a pair of parallel horizontal wells, placed $5 \mathrm{~m}$ apart (in the case of tar sands) in the same vertical plane. The schematic is shown in Figure 6. The top well is the steam injector, and the bottom well serves as the producer. Steam rises to the top of the formation, forming a steam chamber. High reduction in viscosity mobilizes the bitumen, which drains down by gravity and is captured by the producer placed near the bottom of the reservoir. Continuous injection of steam causes the steam chamber to expand and spread laterally in the reservoir. High vertical permeability is crucial for the success of SAGD. The process performs better with bitumen and oils with low mobility, which is essential for the

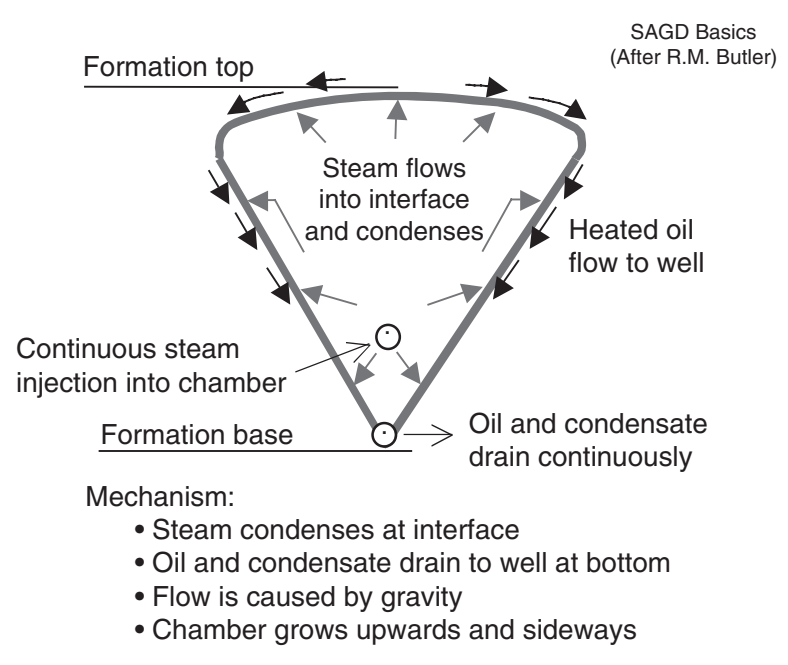

Figure 6

Steam Assisted Gravity Drainage (SAGD).

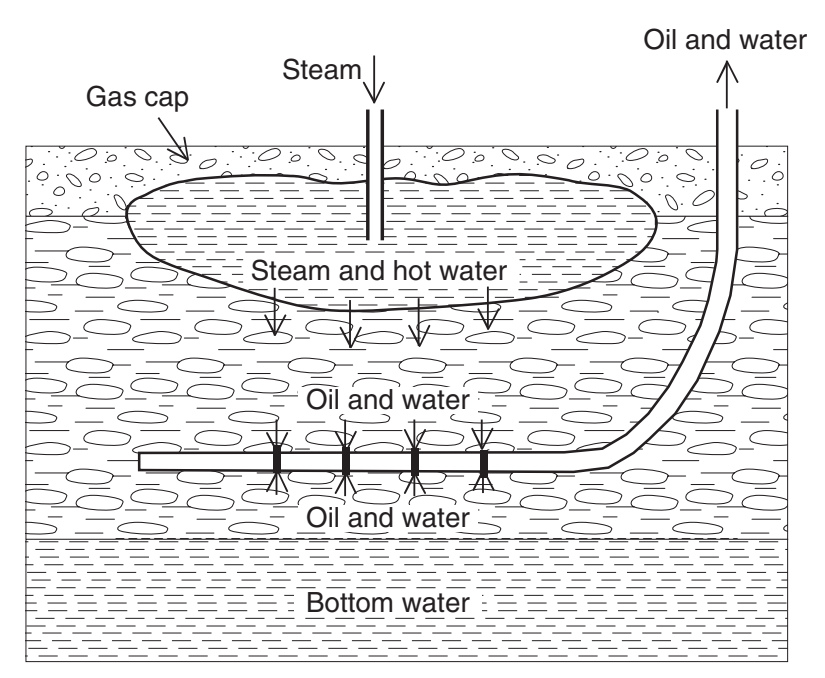

Figure 7

Tangleflags steamflood. 
formation of a steam chamber, and not steam channels. SAGD has been more effective in Alberta than in California and Venezuela for the same reason.

SAGD is highly energy intensive. Large volumes of water are required for steam generation, and the natural gas consumption for steam generation ranges between 200500 tonnes $/ \mathrm{sm}^{3}$ of bitumen. There had been several attempts to improve the economics of SAGD. Notable examples among SAGD variations are VAPEX, ES-SAGD, and SAGP.

\section{SAGD Variations}

VAPEX [7] is the non-thermal counterpart of SAGD, and it works on the same principles as SAGD. Instead of steam, a solvent gas, or a mixture of solvents, such as ethane, propane and butane is injected along with a carrier gas such as $\mathrm{N}_{2}$ or $\mathrm{CO}_{2}$. Solvent selection is based upon the reservoir pressure and temperature. The solvent gas is injected at its dew point. The carrier gas is intended to raise the dew point of the solvent vapour so that it remains in the vapour phase at the reservoir pressure. A vapour chamber is formed and it propagates laterally. The main mechanism is viscosity reduction. The process relies on molecular diffusion and mechanical dispersion for the transfer of solvent to the bitumen for viscosity reduction. Dispersion and diffusion are inherently slow, and therefore, are much less efficient than heat for viscosity reduction.

\section{$E S-S A G D$}

This process (Expanding Solvent SAGD) is another variation, where the addition of about $10 \%$ steam to the solvent mixture has been suggested to gain a $25 \%$ gain in the energy efficiency of VAPEX.

\section{SAGP}

Steam and Gas Push is also a variation, where a non condensable gas such as natural gas or nitrogen, is injected with steam to reduce the high demand of steam in SAGD. These processes are in the early stages of development, and are not proven on a commercial scale.

\section{Special Schemes}

While screening guides are useful tools in selecting a suitable process for a given reservoir, it sometimes requires ingenuity in designing a recovery method for a problem reservoir. One such example is the Tangleflags [8] reservoir on the AlbertaSaskatchewan border. The reservoir is sandstone, with $13 \mathrm{~m}$ thickness. Primary recovery was less than one percent due to severe water coning. Conventional steamflood was unsuitable for this viscous heavy oil reservoir because of the presence of bottom water and a gas cap. The special scheme designed for this reservoir consisted of vertical steam injectors and horizontal producers. The schematic is shown in Figure 7. The vertical wells are completed near the gas cap. Steam and condensed hot water mobilize the oil, which drains down, and is captured by the horizontal wells placed near the bottom of the reservoir. The positive downward pressure gradient minimized water coning. The process has been highly effective, and is currently operating with 11 pairs of wells.

\subsubsection{In Situ Combustion}

In this method, also known as fire flooding [9, 10] air or oxygen is injected to burn a portion $(\sim 10 \%)$ of the in-place oil to generate heat. Very high temperatures, in the range of $450-600^{\circ} \mathrm{C}$, are generated in a narrow zone. High reduction in oil viscosity occurs near the combustion zone. The process has high thermal efficiency, since there is relatively small heat loss to the overburden or underburden, and no surface or wellbore heat loss. In some cases, additives such as water or a gas is used along with air, mainly to enhance heat recovery. Severe corrosion, toxic gas production and gravity override are common problems. In situ combustion has been tested in many places, however, very few projects have been economical and none has advanced to commercial scale.

The main variations of in situ combustion are:

- Forward combustion,

- Reverse combustion,

- High pressure air injection.

In forward combustion, ignition occurs near the injection well, and the hot zone moves in the direction of the air flow, whereas in reverse combustion, ignition occurs near the production well, and the heated zone moves in the direction counter to the air flow. Reverse combustion has not been successful in the field because of the consumption of oxygen in the air before it reaches the production well. High pressure air injection involves low temperature oxidation of the inplace oil. There is no ignition. The process is being tested in several light oil reservoirs in the USA.

\section{THAI and CAPRI Processes}

THAI (Toe-To-Heel Air Injection) and CAPRI [11, 12] (variation of THAI with a catalyst for in situ upgrading) are two other variations of in situ combustion, proposed as economic alternatives of SAGD. These processes utilize a combination of a vertical well and a horizontal well (strategically placed to capture the mobilized oil), as opposed to a pair of horizontal wells for SAGD. The vertical well, placed near the top of the reservoir, is the injector; and the horizontal well, placed near the base of the reservoir, serves as the producer. Initially, steam is injected to establish communication between the injector and the producer. Compressed air from the atmosphere is injected subsequently to bring about ignition/slow oxidation. High temperatures brought on by ignition mobilize the heavy oil/tar sands, which flows from the toe to the heel of the horizontal well. In CAPRI process, it is proposed that the thermally cracked oil, captured by the horizontal well can be economically upgraded to lighter fractions by utilizing a catalytic sheath around the horizontal well. THAI and CAPRI are expected to have higher thermal efficiency and less environmental impact. They have the potential to be applicable to a broader range of reservoirs, 
including thin formations of low pressure, deep reservoirs and reservoirs of poor quality. Recovery factors are estimated to be $70-80 \%$ OIP. Both processes are in the experimental phase and face several technical challenges to overcome.

\subsection{Non-Thermal Methods}

Non-thermal methods [13] are best suited for light oils $(<100 \mathrm{cp})$. In a few cases, they are applicable to moderately viscous oils (<2000 cp), which are unsuitable for thermal methods. The two major objectives in non-thermal methods are:

- lowering the interfacial tension,

- improving the mobility ratio.

Most non-thermal methods require considerable laboratory studies for process selection and optimization. The three major classes under non-thermal methods are: miscible, chemical and immiscible gas injection methods (see Fig. 4). A number of miscible methods have been commercially successful. A few chemical methods are also notable. Among immiscible gas drive processes, $\mathrm{CO}_{2}$ immiscible [14] method has been more successful than others.

\subsubsection{Miscible Flooding}

Miscible flooding [15] implies that the displacing fluid is miscible with the reservoir oil either at first contact (SCM) or after multiple contacts (MCM). A narrow transition zone (mixing zone) develops between the displacing fluid and the reservoir oil, inducing a piston-like displacement. The mixing zone and the solvent profile spread as the flood advances. The change in concentration profile of the displacing fluid with time is shown in Figure 8. Interfacial tension is reduced to zero in miscible flooding, therefore, $N_{c}=\infty$. Displacement efficiency approaches 1 if the mobility ratio is favourable $(M<1)$. The various miscible flooding methods include:

- miscible slug process,

- enriched gas drive,

- vaporizing gas drive,

- high pressure gas $\left(\mathrm{CO}_{2}\right.$ or $\left.\mathrm{N}_{2}\right)$ injection.

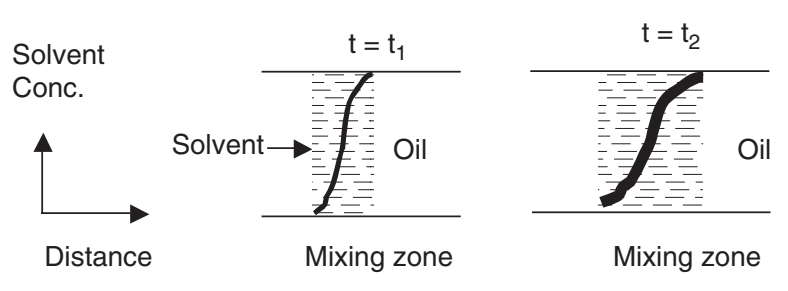

Figure 8

Transition zone and concentration profile of the solvent in miscible flooding.

\section{Miscible Slug Process}

It is an SCM (single contact miscible) type process, where a solvent, such as propane or pentane, is injected in a slug form (4-5\% HCPV). The miscible slug is driven using a gas such as methane or nitrogen, or water. This method is applicable to sandstone, carbonate or reef-type reservoirs, but is best suited for reef-type reservoirs. Gravity segregation is the inherent problem in miscible flooding. Viscous instabilities can be dominant, and displacement efficiency can be poor. Reef-type reservoirs can afford vertical gravity stabilized floods, which can give recoveries as high as 90\% OOIP. Several such floods have been highly successful in Alberta, Canada. Availability of solvent and reservoir geology are the deciding factors in the feasibility of the process. Hydrate formation and asphaltene precipitation can be problematic.

\section{Enriched Gas Drive}

This is an MCM type process, and involves the continuous injection of a gas such as natural gas, flue gas or nitrogen, enriched with $\mathrm{C}_{2}-\mathrm{C}_{4}$ fractions. At moderately high pressures (8-12 MPa), these fractions condense into the reservoir oil and develop a transition zone. Miscibility is achieved after multiple contacts between the injected gas and the reservoir oil. Increase in oil phase volume and reduction in viscosity contrast can also be contributing mechanisms towards enhanced recovery. The process is limited to deep reservoirs (>6000 ft) because of the pressure requirement for miscibility.

\section{Vaporizing Gas Drive}

This also is an MCM type process, and involves the continuous injection of natural gas, flue gas or nitrogen under high pressure (10-15 MPa). Under these conditions, the $\mathrm{C}_{2}-\mathrm{C}_{6}$ fractions are vaporized from the oil into the injected gas. A transition zone develops and miscibility is achieved after multiple contacts. A limiting condition is that the oil must have sufficiently high $\mathrm{C}_{2}-\mathrm{C}_{6}$ fractions to develop miscibility. Also, the injection pressure must be lower than the reservoir saturation pressure to allow vaporization of the fractions. Applicability is limited to reservoirs that can withstand high pressures.

\section{$\mathrm{CO}_{2}$ Miscible}

$\mathrm{CO}_{2}$ Miscible [16] method has been gaining prominence in recent years, partly due to the possibility of $\mathrm{CO}_{2}$ sequestration. Apart from environmental objectives, $\mathrm{CO}_{2}$ is a unique displacing agent, because it has relatively low minimum miscibility pressures (MMP) with a wide range of crude oils. $\mathrm{CO}_{2}$ extracts heavier fractions $\left(\mathrm{C}_{5}-\mathrm{C}_{30}\right)$ from the reservoir oil and develops miscibility after multiple contacts. The process is applicable to light and medium light oils $\left(>30^{\circ} \mathrm{API}\right)$ in shallow reservoirs at low temperatures. $\mathrm{CO}_{2}$ requirement is of the order of $500-1500 \mathrm{sm}^{3} / \mathrm{sm}^{3}$ oil, depending on the reservoir and oil characteristics. Many injection schemes are in use for this method. Particularly notable among them is the WAG (Water Alternating Gas) process, were water and $\mathrm{CO}_{2}$ 
are alternated in small slugs, until the required $\mathrm{CO}_{2}$ slug size is reached (about 20\% HCPV). This approach tends to reduce the viscous instabilities. Cost and availability and the necessary infrastructure of $\mathrm{CO}_{2}$ are therefore major factors in the feasibility of the process. Asphaltene precipitation can be a problem in some cases. Currently there are $80 \mathrm{CO}_{2}$ floods in North America.

\section{$\mathrm{N}_{2}$ Miscible}

This process is similar to $\mathrm{CO}_{2}$ miscible process in principle and mechanisms involved to achieve miscibility, however, $\mathrm{N}_{2}$ has high MMP with most reservoir oils. This method is applicable to light and medium light oils ( $>30^{\circ}$ API), in deep reservoirs with moderate temperatures. Cantarell $\mathrm{N}_{2}$ flood project in Mexico is the largest of its kind at present, and is currently producing about $500000 \mathrm{~B} / \mathrm{D}$ of incremental oil [17].

\subsubsection{Chemical Flooding}

Chemical methods $[18,19]$ utilize a chemical formulation as the displacing fluid, which promotes a decrease in mobility ratio and/or an increase in the capillary number. Many commercial projects were in operation in the 1980's, among which, some were successful, but many were failures. The current chemical floods activity is low, except in China. The future holds promise because of the high demand for energy, and also because of the advancement in technology. Considerable experience and understanding have been gained from the past chemical floods projects. Economics is the major deterrent in the commercialization of chemical floods. It must also be noted that the technology does not exist currently for reservoirs of certain characteristics. The major chemical flood processes are polymer flooding, surfactant flooding, alkaline flooding, micellar flooding and ASP (alkalisurfactant-polymer) flooding (see Fig. 4). Other methods tested include emulsion, foam and the use of microbes, but their impact has not been significant on EOR production thus far.

\section{Polymer Flooding}

Water soluble polymers, such as polyacrylamides and polysaccharides are effective in improving mobility ratio and reducing permeability contrast. In most cases, polymer flooding [20] is applied as a slug process (20-40\% PV) and is driven using dilute brine. Polymer concentration is between 200-2000 ppm. There were many polymer floods in the past, but recoveries were less than $10 \%$ in most cases. The major limitations include loss of polymer to the porous medium, polymer degradation and in some cases, loss of injectivity. One of the common reasons for the failure of polymer floods in the past was that it was applied too late in the waterflood, when the mobile oil saturation was low. The process will be more effective if applied earlier during a waterflood, at water breakthrough, for example, when the oil saturation is above the residual oil saturation.

\section{Surfactant Flooding}

Surfactants are effective in lowering interfacial tension between oil and water. Petroleum sulfonates or other commercial surfactants are often used. An aqueous surfactant slug is followed with a polymer slug, and the two chemical slugs are driven using brine. There were a number of surfactant floods in the past, but they were largely ineffective, mainly due to excessive surfactant loss to the porous medium. Surfactant adsorption and reactions with the rock minerals $[21,22]$ were severe in some cases. Treatment and disposal of emulsions were also of concern.

\section{Alkaline Flooding}

In alkaline flooding $[23,24]$ an aqueous solution of an alkaline chemical, such as hydroxide, carbonate or orthosilicate of sodium, is injected in a slug form. The alkaline chemical reacts with the acid components of the crude oil and produces the surfactant in situ. IFT reduction is the main mechanism. Spontaneous emulsification may also take place. Drop entrainment or drop entrapment may occur depending on the type of emulsion formed, which may enhance or diminish the recovery. Alkalis can cause changes in wettability [25], however, large concentrations are required for wettability alterations. Field results have been discouraging (RF 0-3\% OIP). The process is complex to design due to the various reactions that take place between the alkaline chemical and the reservoir rock and fluids.

\section{Micellar Flooding}

Micellar flooding [26, 27] has been more successful in the field than other chemical flooding processes. The main components of this method are a microemulsion slug (also known as a micellar slug) and a polymer slug. These two slugs are driven using brine. Microemulsions are surfactant-stabilized, oil-water dispersions with small drop size distributions $\left(10^{-4}\right.$ to $10^{-6} \mathrm{~mm}$ ). Microemulsions can be "miscible" with reservoir oil as well as water. The two chemical slugs are designed such that ultra low IFT $\left(10^{-2} \mathrm{mN} / \mathrm{m}\right.$ or lower $)$ and favourable mobility ratio prevails during the most part of the displacement. The process has been tested in 45 field projects, and it has been proven that the method is successful in banking and producing the residual oil left after a waterflood. Recovery factors ranged between $35-50 \%$ OIP in field projects. However, economics were unattractive due to the high cost of chemicals, the requirement of small well spacing, the high initial expense and the considerable delay in response. Moreover, the geology and conditions in many candidate reservoirs (high salinity, temperature and clay content) are unsuitable for the application of micellar flooding. The process holds potential, and deserves to be re-evaluated under the current economic conditions. Scaling groups [28] have been derived for micellar flooding, which is a valuable tool for laboratory evaluation to reduce the risk in the field application of the process. 


\section{ASP Flooding}

Alkaline-Surfactant-Polymer flooding [29, 30] is relatively new and is being evaluated through laboratory investigations as well as field tests. The method utilizes mainly three chemical formulations - alkali, surfactant and polymer solutions. The chemical slugs may be injected in sequence or more likely, as a premixed single slug. The major mechanisms are IFT reduction and improvement in mobility ratio. Field results are encouraging (RF 25-30\% OIP). The method is capable of banking and producing residual oil. The process holds potential, however, the mechanisms are not fully understood. Economics are marginal at best.

\subsubsection{Other Methods}

A few other methods, including combination methods such as Surfactant-Steam, Steam-Foam, and Micellar-ASP, were also tested for EOR. Notable among them are Microbial method and Foam Flooding.

\section{Microbial EOR (MEOR)}

Microbial EOR [31, 32] has been researched since the 1960 's. A few field tests have also been carried out in the USA and other countries. Microbes react with a carbon source, such as oil and produce surfactant, slimes (polymers), biomass and gases such as $\mathrm{CH}_{4}, \mathrm{CO}_{2}, \mathrm{~N}_{2}$ and $\mathrm{H}_{2}$ as well as solvents and certain organic acids. Oil recovery mechanisms in microbial EOR are those of the classic chemical methods, which include IFT reduction, emulsification, wettability alteration, improved mobility ratio, selective plugging, viscosity reduction, oil swelling and increased reservoir pressure due to the formation of gases. Increase in permeability can result from the acids formed. Microbes can be indigenous or exogenous. Exogenous microbes must adapt to reservoir temperature, salinity and hardness. Nutrients, such as molasses or ammonium nitrate are supplied to stimulate microbial growth in the reservoir. The process has advanced since its inception, and is receiving renewed interest in recent years. Performance rating is pending due to insufficient field trials.

\section{Foam Flooding}

Foam has been evaluated as an EOR agent since the early 1960 's. It is a complex non-Newtonian fluid with properties and characteristics governed by many variables [33]. Foam is a dispersion of a liquid (containing surfactant) in a gas such as $\mathrm{CO}_{2}$, air, $\mathrm{N}_{2}$, steam or natural gas. Simultaneous injection of a gas and surfactant solution, or the injection of a gas into the porous medium containing a surfactant solution, generates foam in situ. Foam forms, breaks and re-forms in the pore throats as fluids advance in the porous medium. The presence of oil inhibits the formation of foam, and is therefore not effective in mobilizing residual oil. Mobility of foam is lower than that of gas or steam, and it acts as a viscous fluid. Foam has been used (with limited success), as a mobility control agent or blocking agent, with steam and $\mathrm{CO}_{2}$ in some reservoirs.

\subsection{Current Status OF EOR}

Most of the EOR activity took place in the USA in the past, and the bulk of the production came from that country. Figure 9 shows the EOR production during the last 20 years in USA. The total EOR production in USA is declining [34]. The major contributor was thermal methods, and that is also on the decline, mainly because most attractive reservoirs have already been exploited. Production from gas injection is increasing, and that is mainly due to $\mathrm{CO}_{2}$ floods. Production from chemical floods is non-existent at present. The total EOR production in the USA today constitutes about $12 \%$ of the total domestic oil production.

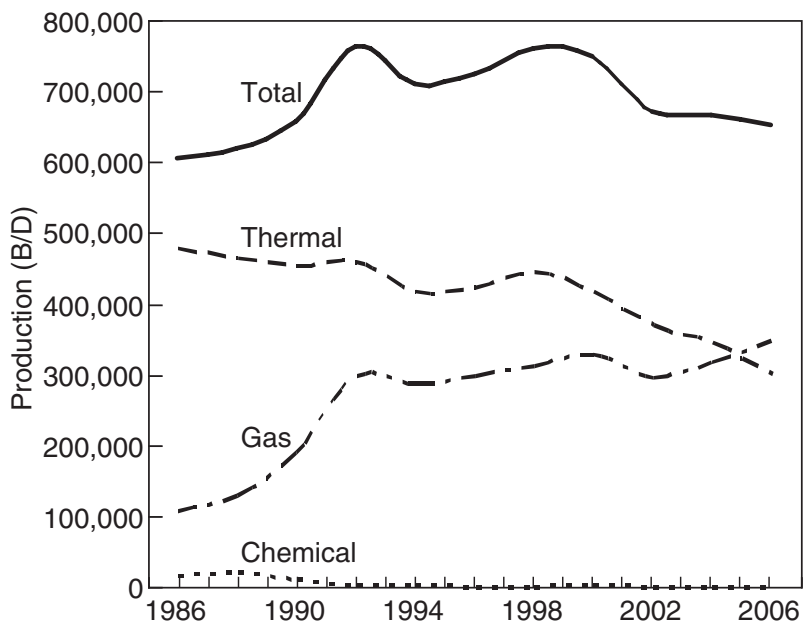

Figure 9

EOR production in the USA.

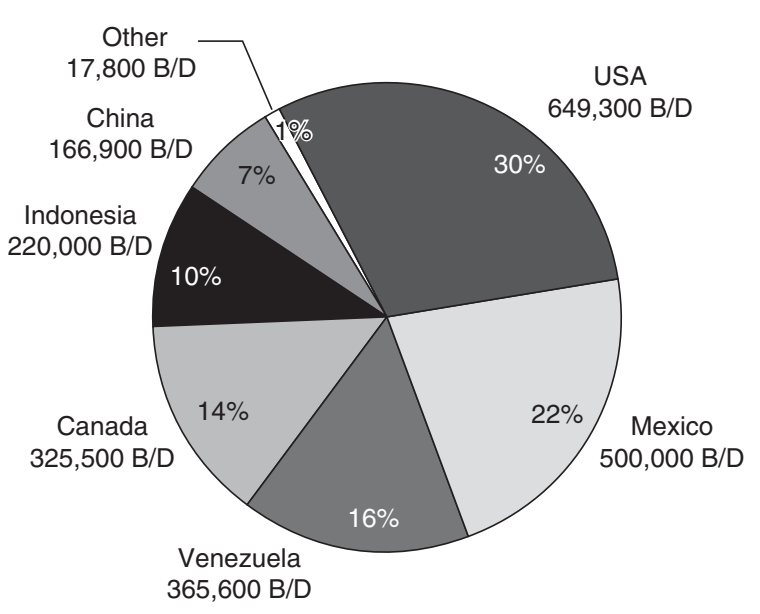

Figure 10

Current EOR production from contributing countries. (Percentages are those of the total EOR production of 2.5 million $\mathrm{B} / \mathrm{D}$.) 


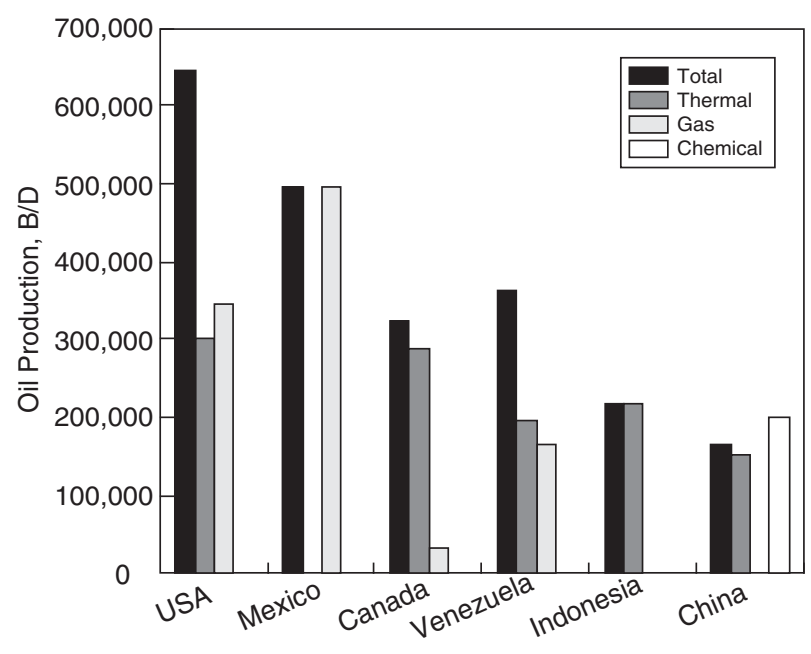

Figure 11

Major EOR projects and production worldwide.

The total world oil production today (including condensate and natural gas liquids) is 84.5 million $\mathrm{B} / \mathrm{D}$. EOR production worldwide is about $2.5 \times 10^{6} \mathrm{~B} / \mathrm{D}$, and almost all of it comes from USA, Mexico, Venezuela, Canada, Indonesia and China, as seen in Figure 10. Figure 11 shows the breakdown of the production from the contributing countries. Thermal methods are dominant in five countries. Chemical floods are active in China, the total production being 200000 B/D in 2006.

Recent advancements in technology and the current economic climate have resulted in a renewed interest in EOR. Future growth of EOR will depend on both technology and oil price. Long term commitments in capital and human resources, as well as in $\mathrm{R} \& \mathrm{D}$, are essential for success in EOR practice. While EOR screening methods are useful tools, recovery methods that are considered unattractive in most reservoirs can be applicable in specific situations. Also, proven EOR methods may be adapted to adverse conditions, as experienced in Canada. Considering the widening gap between demand and supply of energy, EOR will continue to play a significant role in improving recovery factors.

\section{CONCLUSIONS}

- Among the many EOR methods tested, only a few have been commercially successful.

- Steam injection based recovery methods, such as CSS and steamflooding have been highly successful for heavy oils and tar sands.

- Miscible $\mathrm{CO}_{2}$ flooding has had considerable success for light oils, although economics are not clear at this stage.

- Chemical methods such as micellar flooding and ASP hold promise for the recovery of some of the $2 \times 10^{12}$ barrels left in the reservoirs worldwide.

\section{REFERENCES}

1 Owens W.D., Suter V.E. (1965) Steam Stimulation - Newest Form of Secondary Petroleum Recovery, Oil and Gas J. 82-87, 90 .

2 Denbina E.S., Boberg T.C., Rotter M.B. (1991) Evaluation of Key Reservoir Drive Mechanisms in the Early Cycles of Steam Stimulation at Cold Lake, SPE Reservoir Engineer. 207-211.

3 Farouq Ali S.M., Meldau R.F. (1979) Current Steamflood Technology, J. Petrol. Technol., 1332-1342.

4 Stokes D.D., Doscher T.M. (1974) Shell Makes a Success of Steam Flood at Yorba Linda, Oil and Gas J., 71-76.

5 Farouq Ali S.M. (1982) Steam Injection Theory - A Unified Approach, paper SPE 10746, California Regional Meeting of the Society of Petroleum Engineers, San Francisco, March 24-26, 1982.

6 Butler R.M. (1985) A New Approach to the Modeling of Steam-Assisted Gravity Drainage, J. Can. Petrol. Technol., 42-50.

7 Das S.K., Butler R.M. (1995) Extraction of Heavy Oil and Bitumen using Solvents at Reservoir Pressure, paper No. 95118, Proceeding of the Sixth Petroleum Conference of the South Saskatchewan Section of the Petroleum Society of CIM, Regina, Sask., Oct. 16-18, 1995.

8 Jespersen P.J., Fontaine T.J.C. (1993) Tangleflags North Pilot: A Horizontal Well Steamflood, J. Can. Petrol. Technol. 32, 5, 52-57

9 Chu Cheih (1977) A Study of Fireflood Field Projects, paper SPE 5821, J. Petrol. Technol., 111-120.

10 Chu Cheih (1982) State-of-the-Art Review of Fireflood Field Projects, paper SPE 9772, J. Petrol. Technol., 19-32.

11 Greaves M., Xia T.X., Imbus S., Nero V. (2004) THAI-CAPRI Processes: Tracing downhole upgrading of heavy oil, Paper 067, Proceedings of the Canadian International Petroleum Conference, Calgary, Alberta, Canada, June 8-10, 2004.

12 Greaves M., Xia T.X. (2004) Downhole Catalytic process for Upgrading Heavy Oil: Produced Oil Properties and Composition, J. Can. Petrol. Technol. 43, 9, 25-30.

13 Selby Rawya, Alikhan A.A., Farouq Ali S.M. (1989) Potential of Non-thermal Methods for Heavy Oil Recovery, J. Can. Petrol. Technol. 28, 4, 45-59.

14 Nguyen T.A., Farouq Ali S.M. (1988) Effect of Nitrogen on the Solubility and Diffusivity of Carbon Dioxide into Oil and Oil Recovery by the Immiscible WAG Process, J. Can. Petrol. Technol. 37, 2, 24-31.

15 Stalkup Jr. F.I. (1992) Miscible Displacement, Monograph Series, Society of Petroleum Engineers, Richardson, TX, 1992, Vol. 8.

16 Holm L.W. (1959) Carbon dioxide Solvent Flooding for Increased Oil Recovery, Trans. AIME 216, 225-231.

17 Sanchez L., Astudillo A., Rodriguez F., Morales J., Rodriguez A. (2005) Nitrogen Injection in the Cantarell Complex: Results after Four Years of Operation, SPE 97385, Proceedings of the Latin American and Caribbean Petroleum Engineering Conference, Rio de Janeiro, Brazil, June 20-23, 2005.

18 Thomas S., Farouq Ali S.M. (1999) Status and Assessment of Chemical Oil Recovery Methods, Energy Sources 21, 177-189.

19 Thomas S., Farouq Ali S.M. (1993) Field Experience with Chemical Oil Recovery Methods, Proceeding of the 21st Australian Chemical Engineering Conference (Chemeca 93), Melbourne, Australia, Sept. 26-29, 1993, pp. 45-3-49-3. 
20 Chang H.L. (1978) Polymer Flooding Technology Yesterday, Today and Tomorrow, SPE 7043, J. Petrol. Technol. 30, 8, 1113-1128.

21 Somasundaran P, Hanna H.S. (1979) Adsorption of Sulfonates on Reservoir Rocks, SPE 7059, SPE J., 221-232.

22 Krumrine P.H., Falcone Jr. J.S. (1983) Surfactant, Polymer and Alkali Interactions in Chemical Flooding Processes, paper SPE 11778, Proceeding of the SPE International Symposium on Oilfield and Geothermal Chemistry, Denver, CO, June 1-3, 1983, pp. 79-86.

23 Mayer E.H., Breg R.L., Carmichael J.D., Weinbrandt R.M. (1983) Alkaline Injection for Enhanced Oil Recovery - A status report, J. Petrol. Technol., 209-221.

24 Johnson Jr. C.E. (1976) Status of Caustic and Emulsion Methods, J. Petrol. Technol., 85-96.

25 Froning H.R., Leach R.O. (1967) Determination of Chemical Requirement and Applicability of Wettability Alteration Flooding, J. Petrol. Technol., 839-843.

26 Gogarty W.B., Tosch W.C. (1968) Miscible-type Waterflooding: Oil Recovery with Micellar Solutions, J. Petrol. Technol., 1407-1414.

27 Farouq Ali S.M., Thomas S. (1986) Tertiary Oil Recovery of Two Alberta Oils by Micellar Flooding, Proceedings of the 37th Annual Technical Meeting of the Petroleum Society of CIM, Calgary, Alberta, June 8-11, 1986, pp. 159-184.
28 Thomas S., Farouq Ali S.M. (2001) Scale-up Methods for Micellar Flooding and their Verification, J. Can. Petrol. Technol. 39, 2, 18-27.

29 Wyatt K., Pitts M.J., Surkalo H. (2002) Mature Waterfloods Renew Oil Production by Alkaline-Surfactant-Polymer Flooding, SPE 78711, Proceedings of the SPE Eastern Regional Meeting, Lexington, Kentucky, Oct. 23-25, 2002.

30 Shutang G., Huabin L., Zhenyu Y., Pitts M.J., Surkalo H., Wyatt K. (1996) Alkaline/Surfactant/Polymer Pilot Performance of the West Central Saertu, Daqing Oil Field, SPE Reservoir Engineer., 181-188.

31 Hitzman D.O., Sperl G.T. (1994) A New Microbial Technology for Enhanced Oil Recovery and Sulphide Prevention and Reduction, SPE/DOE 27752, Proceedings of the SPE/DOE ninth Symposium on Improved Oil Recovery, Tulsa, OK, USA, April 17-20, 1994, pp. 171-179.

32 Bryant R.S. (1994) Microbial Enhanced Hydrocarbon Recovery and its Potential for Application to North Sea Reservoirs, Trans IChemE 72, Part A, 144-151.

33 Farouq Ali S.M., Selby Rawya J. (1986) Function, Characteristics of EOR Foam Behaviour Covered in Laboratory Investigations, Technology, Oil and Gas J. 57, 60-63.

34 Moritis G. (2006) Special Report - EOR/Heavy Oil Survey, Oil and Gas J., 37-55.

Final manuscript received in July 2007 